\title{
Prevalence and factors associated with CrossMark inappropriate use of treadmill exercise stress test for coronary artery disease: a cross-sectional study
}

Antônio M. L. Silva ${ }^{1 *}$, Anderson C. Armstrong ${ }^{2}$, Fernando J. C. Silveira ${ }^{2}$, Marcelo D. Cavalcanti ${ }^{2}$, Fernando M. F. França ${ }^{2}$ and Luis C. L. Correia'

\begin{abstract}
Background: In some countries, the public health system has less availability when compared to the population covered by health insurance. In addition, inappropriate referrals for treadmill exercise stress test increase spending and lead to unnecessary interventions. We aim to determine the prevalence and characteristics of inappropriate referrals for treadmill exercise stress tests in the assessment of coronary artery disease (CAD), considering public and private health systems scenarios.

Methods: A cross-sectional design was used to describe the frequency of inappropriate use of exercise testing in the diagnosis of CAD and to determine its predictors. We consecutively enrolled 191 patients from two outpatient facilities in Northeast Brazil. For inclusion, the exercise testing should be referred for the assessment of CAD. We performed logistic regression models to identify independent predictors of inappropriate use.
\end{abstract}

Results: Treadmill exercise stress tests were rated as inappropriate in 150 (78\%) patients. The majority of patients had low or very low pre-test probability of CAD. Presence of hypertension, diabetes and dyslipidemia were more frequent in the appropriate than inappropriate indications (71 \%, $19 \%$ and $29 \%$ versus $43 \%, 8 \%$ and $16 \%$, respectively). Tests performed both at the public and private system showed high prevalence of inappropriate examinations, higher in the latter ( $57 \%$ versus $87 \%, P<0.001)$. The private health system was the major independent predictor of inappropriate referral, consistent in all regression models (when adjusting for clinical variables, $\mathrm{OR}=4.3 ; \mathrm{P}<0.001)$.

Conclusion: The vast majority of treadmill exercise stress test referrals in the assessment of CAD were inappropriate. The availability of the method and not the estimate probability of CAD appear to be the underlying condition for a treadmill test referral.

Keywords: Exercise testing, Treadmill test, Coronary artery disease, Appropriateness criteria

\section{Background}

Evidence has failed to show that an aggressive screening for coronary artery disease (CAD) may improve cardiovascular goals in primary prevention. Also, searches for ischemic response in asymptomatic CAD patients are not related to favorable outcomes [1]. The treadmill exercise stress test appears to be particularly vulnerable to overuse in clinical settings, due to its wide availability and affordability. The inappropriate use of the method,

\footnotetext{
* Correspondence: antonio2774@hotmail.com

'School of Medicine and Public Health, Salvador, Brazil

Full list of author information is available at the end of the article
}

however, may result in overdiagnosis and overtreatment of coronary artery disease $[2,3]$.

Developing countries in which private and public health systems coexist have limited funding for health. In developed countries that also have universal health care systems such as France and Germany, investment in health was about five times higher [4]. The inappropriate use of procedures contributes to the waste of resources that could enhance benefits to the population to be assisted, if they were utilized rationally. Even in developed countries, the growing expenditure on health is a major concern. At least $20 \%$ of health spending in the 
US represent unnecessary expenses, where the inappropriate use of diagnostic evaluations contribute to this number [5].

Studies that assess inappropriate use of exercise stress tests and their impact remain scarce. This study aimed to assess the frequency and the determinants of an inappropriate use of treadmill exercise stress tests for CAD in outpatient public and private facilities.

\section{Methods}

\section{Study population}

Between November 2012 and April 2013, we consecutively enrolled patients aged $\geq 18$ years, who had been referred to treadmill exercise stress tests for evaluation of CAD from two outpatient facilities in Northeast Brazil. All patients underwent a clinical assessment by experienced cardiologists to evaluate symptoms and risk factors. The pretest probability for CAD was determined based on Diamond-Forrester algorithm, which takes into account chest pain characteristics, age, and sex [6]. The assessment of cardiovascular risk (CV) was defined according to risk prediction of the World Health Organization (WHO), based on sex, age, blood pressure, presence of diabetes and smoking status. Participants were then classified as low if $\mathrm{CV}$ risk was estimated to be $<10 \%$ in ten years, intermediate if between $10 \%$ and $20 \%$, and high cardiovascular risk if above $20 \%$ [7].

We calculated a sample size of 189 participants, based on an accuracy of $\pm 7 \%$ and on an estimate of the inappropriate referrals in $60 \%$ of the treadmill tests. The project was approved by the Ethics Committee in Research of Bahia Foundation for Science Development, Brazil. The term informed consent was obtained from all participants.

\section{Definition of inappropriate use of treadmill exercise stress test}

There is no specific guideline on appropriate use criteria for treadmill exercise stress test. However based on the evidence of screening in asymptomatic and assessment in those stable patients with CAD, but also the probabilistic concept of using the method according to the probability of coronary artery disease, we defined the inappropriate diagnostic evaluation parameters. Treadmill exercise stress tests were then rated as inappropriate if they presented one of the following two criteria: (1) patients asymptomatic for CAD; (2) symptomatic patients with low or high pretest probability of CAD. Treadmill exercise stress test in individuals above 70 years of age with chest pain was rated as appropriate, as well as those patients symptomatic with known CAD. Individuals younger than 30 years were classified as the likelihood of CAD according to age group 30-39 years in the criteria of Diamond-Forrester.

\section{Statistical analysis}

The prevalence of inappropriate use was described by proportion and its accuracy estimated by a confidence interval at $95 \%$. In univariate analysis, variables were compared between inappropriate versus appropriate tests by the chi-square test for categorical variables and Student $t$ test for numerical variables.

To identify independent predictors of inappropriate use, variables with $\mathrm{P}<0.10$ in the univariate analysis were included in multivariate logistic regression models using the backwards technique. Three logistic regression models were used to represent the associating parameters derived from the univariate analysis. These models are also compared to clinical thinking in the diagnostic evaluation request. The model 1 is adjusted for clinical variables (hypertension, dyslipidemia and diabetes); model 2 for the number of risk factors and the model 3 is associated with cardiovascular risk. These associations were also described by odds ratios and $95 \%$ CI. Variables that remained in the final model with $\mathrm{P}<0.05$ were defined as independent predictors. The calibration of the models was assessed by testing Hosmer-Lemeshow. We used SPSS software for statistical analysis (version 17.0, SPSS Inc., Chicago, USA).

\section{Results}

We consecutively enrolled 221 participants referred to treadmill exercise stress tests. Thirty patients had requests for evaluation of arrhythmia, systemic blood pressure or functional assessment and were excluded from the study. The research or DAC assessment was the indication for treadmill exercise stress test in 191 subjects. The mean age was $48 \pm 14$ years, $66 \%$ were female and half of the patients were asymptomatic. There was a predominance of subjects with pre-test probability for coronary heart disease low or very low (29\% and $44 \%$, respectively) and low cardiovascular risk (80\%), according to the WHO risk prediction. Private health systems diagnostic evaluations represented $71 \%$ of the sample. Other characteristics are described in Table 1.

\section{Prevalence and associated variables of inappropriate treadmill exercise stress tests}

For $150(78 \%)$ participants that underwent treadmill exercise stress tests, the diagnostic evaluations were rated as inappropriate. But both private and public health systems showed high frequencies of inappropriate treadmill exercise stress tests, with higher rates in the private health system ( $87 \%$ and $57 \%$ respectively; $\mathrm{P}<0.001)$.

Participants undergoing inappropriate treadmill exercise stress tests were significantly younger than those who performed appropriate tests $(45 \pm 13$ years vs $60 \pm$ 12 years, $\mathrm{P}<0.001)$. Risk factors such as hypertension, diabetes and dyslipidemia were less frequent when an 
Table 1 Personal Characteristics of Study Sample

\begin{tabular}{|c|c|}
\hline Parameters & Values \\
\hline$n$ & 191 \\
\hline Age (years) & $48 \pm 14$ \\
\hline Male & $85(44 \%)$ \\
\hline \multicolumn{2}{|l|}{ Symptom of chest pain ${ }^{a}$} \\
\hline Asymptomatic & $97(50.8 \%)$ \\
\hline Nonanginal & $80(41.9 \%)$ \\
\hline Atypical angina & $9(4.7 \%)$ \\
\hline Typical angina & $5(2.6 \%)$ \\
\hline \multicolumn{2}{|l|}{ Pre-test probability of CAD } \\
\hline Very low & $84(44 \%)$ \\
\hline Low & $55(28.8 \%)$ \\
\hline Intermediate & $29(15.2 \%)$ \\
\hline High & $1(0.5 \%)$ \\
\hline Not applicable ${ }^{b}$ & $22(11.5 \%)$ \\
\hline Hypertension & $93(49 \%)$ \\
\hline Diabetes & $20(10 \%)$ \\
\hline Dyslipidemia & $36(19 \%)$ \\
\hline Obesity & $48(25 \%)$ \\
\hline Family history of CAD & $41(21 \%)$ \\
\hline Smoker & $12(6.3 \%)$ \\
\hline Known CAD & $12(6.3 \%)$ \\
\hline Previous myocardial infarction & $8(4.2 \%)$ \\
\hline Revascularization & $11(5.8 \%)$ \\
\hline \multicolumn{2}{|l|}{ Cardiovascular risk ${ }^{c}$} \\
\hline Low & $151(80 \%)$ \\
\hline Intermediate & $20(10 \%)$ \\
\hline High & 19 (10 \%) \\
\hline Tests of public health system & $56(29 \%)$ \\
\hline
\end{tabular}

${ }^{\mathrm{a}}$ Symptom in the anamnesis; ${ }^{\mathrm{b}} \mathrm{Age} \geq 70$ years or known CAD; ${ }^{\mathrm{c}}$ Cardiovascular Risk Estimation in 10 years, according to the WHO risk prediction (Low: $<10 \%$, Intermediate: between 10 and $20 \%$, High: $\geq 20 \%$ )

inappropriate referral was identified, reflecting mostly low cardiovascular risk profiles. Additional clinical characteristics were similar between participants with appropriate and inappropriate treadmill exercise stress tests (Table 2).

\section{Independent predictors of inappropriate treadmill exercise stress tests}

Three logistic regression models were used to represent the associating parameters derived from the univariate analysis. Age was not included in the models because this variable was part of the calculation of the pre-test probability (used in the definition of inappropriate use of treadmill exercise stress test). In model 1 , among the clinical variables only hypertension was shown to be inversely associated with inappropriate use of the treadmill
Table 2 Patient Characteristics According to Treadmill Exercise Stress Test Appropriateness Criteria

\begin{tabular}{|c|c|c|c|}
\hline Parameter & $\begin{array}{l}\text { Appropriate } \\
(n=41)\end{array}$ & $\begin{array}{l}\text { Inappropriate } \\
(n=150)\end{array}$ & $P$ Value \\
\hline Male & $21(51 \%)$ & $64(43 \%)$ & 0.32 \\
\hline Age & $60 \pm 12$ & $45 \pm 13$ & $<0.001$ \\
\hline \multicolumn{4}{|l|}{ Clinical conditions } \\
\hline Diabetes & 8 (19\%) & $12(8,0 . \%)$ & 0.03 \\
\hline Dyslipidemia & $12(29 \%)$ & $24(16 \%)$ & 0.05 \\
\hline Hypertension & $29(71 \%)$ & $64(43 \%)$ & 0.001 \\
\hline Obesity & 12 (29 \%) & $36(24 \%)$ & 0.49 \\
\hline Previous infarction & $2(4.9 \%)$ & $6(4.0 \%)$ & 0.68 \\
\hline known CAD & $4(9.8 \%)$ & $8(5.4 \%)$ & 0.29 \\
\hline Revascularization & $4(9.8 \%)$ & $7(4.7 \%)$ & 0.25 \\
\hline Smoker & $1(2.4 \%)$ & $11(7.3 \%)$ & 0.25 \\
\hline Family history of CAD & $10(24 \%)$ & 31 (21\%) & 0.60 \\
\hline Risk factors ${ }^{a}$ & & & 0.03 \\
\hline No risk factor & $6(14,6 \%)$ & $51(34 \%)$ & \\
\hline 1 or 2 risk factors & $25(61 \%)$ & $79(52,7 \%)$ & \\
\hline$>2$ risk factors & $10(24,4 \%)$ & $20(13,3 \%)$ & \\
\hline Cardiovascular risk ${ }^{\mathrm{b}}$ & & & 0.001 \\
\hline Low & $24(58.5 \%)$ & 127 (85.2 \%) & \\
\hline Intermediate & $10(24.4 \%)$ & $10(6.7 \%)$ & \\
\hline High & 7 (17.1 \%) & $12(8.1 \%)$ & \\
\hline Public health system & $24(58 \%)$ & 32 (22 \%) & $<0.001$ \\
\hline
\end{tabular}

exercise stress test. In Model 2 and Model 3 revealed no significant association between the number of risk factors or cardiovascular risk with inappropriate indications for treadmill exercise stress test (Table 3 ). In second moment, we adjusted the model 1 for age, only in order to verify that the inverse association of hypertension with inappropriate testing was mediated by these patients being younger. In fact, hypertension lost statistical significance in this model, while additional network of health remained strongly associated (when adjusting for age, $\mathrm{OR}=3.5 ; \mathrm{P}=0.003)$. Therefore, patient being in the private health care system was the only important significant covariate in the models, with $\mathrm{OR}=4.3(\mathrm{P}<0.001)$, according to the model adjusted for clinical conditions. The $\mathrm{P}$ value of the Hosmer-Lemeshow test for all models was $>0.05$ indicating a good calibration.

\section{Discussion}

In a developing country, we describe the prevalence of inappropriate use of treadmill exercise stress tests for the diagnosis of CAD in public and private health 
Table 3 Predictors in Multivariable Logistic Regression for Inappropriate Use of Treadmill Exercise Stress Test for Coronary Artery Disease

\begin{tabular}{|c|c|c|c|c|c|c|}
\hline & Model 1 & & Model 2 & & Model 3 & \\
\hline Predictors & OR $(95 \%$ IC) & $P$ Value & OR $(95 \%$ IC) & $P$ Value & OR $(95 \%$ IC) & $P$ Value \\
\hline Private health system & $4.3(2.0-9.1)$ & $<0.001$ & $5.1(2.4-10.6)$ & $<0.001$ & $4.7(2.2-10.3)$ & $<0.001$ \\
\hline Clinical conditions & $0.49(0.17-1.5)$ & 0.200 & Not selected & & Not selected & \\
\hline \multirow[t]{2}{*}{ Diabetes } & & 0.505 & & & & \\
\hline & $0.74(0.30-1.8)$ & 0.013 & & & & \\
\hline Dyslipidemia & & 0.186 & & & & \\
\hline Hypertension & $0.37(0.17-0.81)$ & & & & & \\
\hline Obesity & $0.54(0.22-1.3)$ & & & & & \\
\hline Risk factors (reference: without risk factor) & Not selected & & $3.2(0.98-10.6)$ & 0.054 & Not selected & \\
\hline 1 or 2 risk & & & $1.4(0.56-3.7)$ & 0.450 & & \\
\hline \multicolumn{7}{|l|}{ factors } \\
\hline \multicolumn{7}{|l|}{$>2$ risk } \\
\hline \multicolumn{7}{|l|}{ factors } \\
\hline Cardiovascular risk (reference low risk) & Not selected & & Not selected & & $1.9(0.63-5.8)$ & 0.247 \\
\hline Intermediate & & & & & & 0.161 \\
\hline High & & & & & $0.37(0.09-1.5)$ & \\
\hline
\end{tabular}

system facilities. The vast majority of diagnostic evaluations were rated as inappropriate. Being in the private health system increased over 4.3 folds the odds of being referred for an inappropriate treadmill exercise stress test. Moreover, patients' clinical characteristics appear to have had little impact on treadmill referrals.

We showed a remarkably high proportion of inappropriate treadmill exercise stress test in our population, which seems to be in line with other areas of the world. An Italian study evaluated 960 referrals for non-invasive cardiac testing, finding that only a third of the requests were considered appropriate. Moreover, exercise testing had only $27 \%$ of appropriate referrals, showing the worst results among non-invasive cardiac tests [8]. Studies evaluating appropriateness criteria in the use of treadmill exercise stress tests for diagnosis of obstructive CAD are still sparse in the literature. However, evidences show that asymptomatic individuals do not benefit from active screening for obstructive CAD [9-12]. Additionally, mandatory myocardial stress testing in patients with known CAD did not reduce major CV outcomes $[1,13$, 14]. Similarly, individuals in both low and high pre-test probability for obstructive CAD do not benefit from treadmill test screening, as results may not substantially affect the likelihood of disease. Therefore, the main utility of the exercise test in the diagnosis of obstructive CAD lies in symptomatic patients with intermediate pretest probability.

Although we found a high frequency of inappropriate treadmill exercise stress tests among participants from the public health system, inappropriate diagnostic evaluations were even more frequent in patients from the private health care system.

In Brazil two healthcare systems coexist: the public and the private. The evident imbalance between the funding expenses for private and public health in a developing country as Brazil leads to an unequal health policy. In December 2013 there were 2109 offices specialized in the public system, while in the private network had 8937 specialized consultation rooms [15]. It reflects the higher availability of health services in the private healthcare system, compared to the scarce resources in the public system. Although covering only $24 \%$ of the population, about $54 \%$ of the spent in the Brazilian healthcare in 2011 was in the private system. The public health system covers the majority of the Brazilian population, investing around 512 dollars per person per year $[4,16]$. Our multivariable models showed that only being from the private health system was an independent predictor of inappropriate use of treadmill exercise stress test. Remarkably, neither the cardiovascular risk nor the presence of comorbidities tested in our logistic regression models remained significant after adjusting for health system. Apparently, the main variable when deciding to use a treadmill exercise stress test in the study was the availability of the method. The prevalence of heart disease in the age group between 35 and 49 years of age is approximately $3.7 \%$ in Brazil [17]. Indeed, characteristics of the inappropriate sample (mean age of 45 and low cardiovascular risk profiles) do not seem representative of a usual treadmill referral population. These findings are an 
emblem of health consumerism from people who have health insurance and can get (unnecessary) testing.

Irrational use of diagnostic complementary methods directly impacts healthcare spending. The cost of cardiovascular disease is significant in Brazil, with an expense of about $1.74 \%$ of Gross National Product [17]. In 2012, 497,242 treadmill exercise stress tests have been performed in the Brazilian public health system, with a cost of more than $\$ 7$ million US dollars. With our results in mind, nearly 243 thousand exams could be considered inappropriate across Brazil, representing an unnecessary expense of more than $\$ 3$ million dollars in 2012 [18]. In addition to that, inappropriate treadmill exercise stress tests may lead to unnecessary additional procedures, generating potential harm to patients and also increasing costs in health systems. A Canadian study showed that $42 \%$ of 2,718 patients with suspected CAD had a normal cardiac catheterization, although the majority had a previous positive noninvasive stress test [19]. In a US study with 397,954 patients, most elective catheterizations showed no obstructive coronary disease, although over $80 \%$ of the patients underwent a previous noninvasive test [20]. Furthermore, a normal treadmill exercise stress test may negatively affect primary prevention strategies, as the wrong perception of absent coronary disease may prevent susceptible individuals from reducing their modifiable risk factors and overall risk profile.

There are limitations regarding the generalization of our study. In fact, it is a small sample and the results may represent the local reality of a center in Northeastern Brazil. Further research assessing different populations in other health centers may reinforce our findings and broaden the discussion of this important topic.

\section{Conclusion}

We found a high prevalence of inappropriate treadmill exercise stress test referrals for the diagnosis of CAD. This finding was consistent in both private and public health systems, but higher in the private system. Absence of comorbidities such as hypertension, diabetes and dyslipidemia, as well as judgment to estimate cardiovascular risk were not associated with inappropriate indication for use of treadmill exercise test in the diagnosis of obstructive CAD. In fact, the private health care system was the only predictor of inappropriate indications. It is likely that the greater availability of complementary method in that system, favoring its inappropriate use. Our findings may provide insights that favor the judicious use of medical resources even when largely available, focusing on the best evidence and the appropriate use of the complementary method diagnostic.

\section{Competing interests}

The authors declare that they have no competing interests.

\section{Authors' contributions}

AS performed the study, enrolled patients, performed the analysis, drafted the manuscript, read and approved the final manuscript; AA participated in the analysis, contributed to the manuscript, read and approved the final manuscript; FS did data entry, participated in the analyses, read and approved the final manuscript; MC enrolled patients, contributed to the manuscript, read and approved the final manuscript; FF enrolled patients, contributed to the manuscript, read and approved the final manuscript; LC participated in the design of the study and its coordination, supervised the analysis, contributed to the manuscript, read and approved the final manuscript.

\section{Authors' information}

Antônio M. L. da Silva

\section{Author details}

${ }^{1}$ School of Medicine and Public Health, Salvador, Brazil. ${ }^{2}$ University of São Francisco Valley -UNIVASF, Petrolina, Brazil.

Received: 21 February 2015 Accepted: 1 June 2015

Published online: 16 June 2015

\section{References}

1. Harb SC, Cook T, Jaber WA, Marwick TH. Exercise testing in asymptomatic patients after revascularization: Are outcomes altered? Arch Intern Med. 2012;172(11):854-61.

2. Ray M, Jenny D, David H. Preventing overdiagnosis: how to stop harming the healthy. BMJ. 2012;344, e3502.

3. Lasse TK, Karsten JJ, Christian GL, Peter CG. General health checks in adults for reducing morbidity and mortality from disease: Cochrane systematic review and meta-analysis. BMJ. 2012;345, e7191.

4. World Health Organization. Publications [Internet]. World Health Statistics 2014.[cited 2014 Sep 20]. Available from: http://www.who.int/gho/ publications/world_health_statistics/en/.

5. Berwick DM, Hackbarth AD. Eliminating waste in us health care. JAMA. 2012;307(14):1513-6.

6. Diamond GA, Forrester JS. Analysis of probability as an aid in the clinical diagnosis of coronary-artery disease. N Engl J Med. 1979;300(24):1350-8.

7. World Health Organization. Publications [Internet]. Prevention of Cardiovascular Disease: guidelines for assessment and management of cardiovascular risk. 2007. [cited 2014 Mar 21]. Available from: http:// www.who.int/cardiovascular_diseases/publications/ Prevention_of_Cardiovascular_Disease/en/.

8. Orsini E, Lorenzoni R, Becherini F, Giaconi S, Levantesi D, Lucarini A, et al. Appropriateness of prescription of exercise stress test, echocardiography, Holter monitoring and vascular echography. G Ital Cardiol (Rome). 2007;8(6):359-66.

9. Cassel CK, Guest JA. Choosing wisely: Helping physicians and patients make smart decisions about their care. JAMA. 2012;307(17):1801-2.

10. McEvoy JW, Blaha MJ, Nasir K. Impact of coronary computed tomographic angiography results on patient and physician behavior in a low-risk population. Arch Intern Med. 2011;171(14):1260-8.

11. Gibbons RJ, Miller TD, Hodge D, Urban L, Araoz PA, Pellikka P, et al. Application of appropriateness criteria to stress single-photon emission computed tomography sestamibi studies and stress echocardiograms in an academic medical center. J Am Coll Cardiol. 2008;51(13):1283-9.

12. Chou R, Arora B, Dana T, Fu R, Walker M, Humphrey L. Screening Asymptomatic Adults With Resting or Exercise Electrocardiography: A Review of the Evidence for the U.S. Preventive Services Task Force. Ann Intern Med. 2011;155(6):375-85.

13. Babapulle M, Diodati J, Blankenship J, Huynh T, Cugno S, Puri R, et al. Utility of routine exercise treadmill testing early after percutaneous coronary intervention. BMC Cardiovasc Disord. 2007;7(1):12.

14. Wolk MJ, Bailey SR, Doherty JU, Douglas PS, Hendel RC, Kramer CM, et al. ACCF /AHA /ASE /ASNC / HFSA / HRS / SCAI / SCCT / SCMR / STS 2013 Multimodality Appropriate Use Criteria for the Detection and Risk Assessment of Stable Ischemic Heart Disease. A Report of the American College of Cardiology Foundation Appropriate Use Criteria Task Force, American Heart Association, American Society of Echocardiography, 
American Society of Nuclear Cardiology, Heart Failure Society of America, Heart Rhythm Society, Society for Cardiovascular Angiography and Interventions, Society of Cardiovascular Computed Tomography, Society for Cardiovascular Magnetic Resonance, and Society of Thoracic Surgeons. J Am Coll Cardiol. 2013;63(4):380-406.

15. Ministry of Health, Brazil. DATASUS [Internet]. SUS especialized clinic, 2013. [cited 2015 Mai 05]. Available from: http://tabnet.datasus.gov.br/cgi/ tabcgi.exe?cnes/cnv/consulbr.def.

16. National Health Agency, Brazil. ANS TABNET [Internet]. Health Insurance Coverage. 2012 [cited 2014 Sep 14]. Available from: http://www.ans.gov.br/ anstabnet/cgi-bin/dh?dados/tabnet_tx.def.

17. Balbinotto NG, Silva END. The costs of cardiovascular disease in Brazil: a brief economic comment. Arq Bras Cardiol. 2008;91(4):217-8.

18. Ministry of Health, Brazil. DATASUS [Internet]. SUS outpatient production, 2012. [cited 2014 Jul 26]. Available from: http:/tabnet.datasus.gov.br/cgi/ tabcgi.exe?sia/cnv/qauf.def.

19. Levitt K, Guo H, Wijeysundera HC, Ko DT, Natarajan MK, Feindel CM, et al. Predictors of normal coronary arteries at coronary angiography. Am Heart J. 2013;166(4):694-700.

20. Patel MR, Peterson ED, Dai D, Brennan JM, Redberg RF, Anderson HV, et al. Low Diagnostic Yield of Elective Coronary Angiography. N Engl J Med. 2010;362(10):886-95.

\section{Submit your next manuscript to BioMed Central and take full advantage of:}

- Convenient online submission

- Thorough peer review

- No space constraints or color figure charges

- Immediate publication on acceptance

- Inclusion in PubMed, CAS, Scopus and Google Scholar

- Research which is freely available for redistribution 